\title{
Female Body Anthropometric Variation and Breakthrough in Anthropology for Digital Modelling
}

\author{
Badriatut Dini ${ }^{1}$, M R Hutagalung ${ }^{1}$, D S.Perdanakusuma ${ }^{1}$, Phill T Koesbandriati ${ }^{2}$, and Agus Windharto ${ }^{3}$
}

\begin{abstract}
Plastic reconstructive and aesthetic surgery has emerged to meet the challenge of improving body size and shape. Currently, body reconstruction in Indonesia refers to Caucasian parameters which may not be applicable. Moreover, patients cannot comprehend the surgeon's prediction of the surgical outcome visually making it more difficult for the surgeon to describe the operative result. Reseach Objective is understanding the supernormal body concept in Indonesia, describing variation of normal and supernormal body indexes of Indonesians as a formulation base and to make a $3 D$ digital modeling of normal and supernormal person. These models will be used as guidance for planning and predicting the reconstruction aesthetic surgery in body contouring and as assisting tool for giving information visually to patients. Reseach method using applied study. Questionnaires were distributed to a hundred male and female adults respondent to obtain the concept of Indonesian normal and supernormal bodies. The Body model are 17-25 years old and then divided into 2 groups, normal and supernormal by expert juries assessment. The data of body index anthropometry were presented in tables, charts, and narration to describe normal and supernormal morphologic variations, then results between the 2 groups were compared statistically by $t$ test and discriminant test. Anthropometric and photographic data were used for making normal and supernormal 3D digital woman models. Criteria of body attractiveness by questionnaire were bright skin color, tallness, slimness, hour glass body shape, muscular arms, medium sized shoulders, hip, waist, breasts and buttocks, wide chest and slender legs. There were significant differences in body measurement between normal-supernormal and distinguishing parameters between normal -supernormal groups by discriminant test including chest dimension index, waist hip ratio, triceps skinfold and leg length. There were two $3 D$ digital woman models for both normal and supernormal subjects which had measurements approximating the average values of each group.
\end{abstract}

Keywords— body measurement, contouring, 3D digital modeling, reconstructive and aesthetic.

\section{INTRODUCTION}

$\mathrm{T}$ he human body and appearance play an important role in human life becoming identity for some [1-2] The beauty standard is difference in times and places [311]. Body contouring can provide a solution for improving quality of one's appearance. Some techniques for augmenting or reducing parts of the human body to make it more attractive have been developed like abdominoplasty, mastopexy, liposuction, breast reduction and augmentation [12-15]. Differences in race, geographic and socioeconomic condition closely relate to differences in body anthropometric measurements[1619]. All this time, the standard measurement used in body contouring have referred to Caucasian parameters which may not be applicable[12-15]

In body contouring, the preoperative planning includes predicted body measurement and operative design is very important. Three dimension (3D) scan has been used to assess preoperative and postoperative body conditions in some centers, but it cannot be used as a model for making quantitative operative planning[2021].

In this study, the researcher built an anthropometric database of the Indonesian'people taken from clinical anthropometric and body photography of 44 normal and 48 attractive female students's bodies in Surabaya, the

${ }^{1}$ Badriatut Dini, M R Hutagalung, and D S.Perdanakusuma are with Departement of Plastic Surgery, Universitas Airlangga, Surabaya, Indonesia. E-mail: ayinkdr@yahoo.co.id.

${ }^{2}$ Phill $\mathrm{T}$ Koesbandriati is with Departement of Anthropology, Universitas Airlangga, Surabaya, Indonesia.

${ }^{3}$ Agus Windharto is with Departement of Industrial Design, Faculty of Civil Engineering and Planning, Institut Teknologi Sepuluh Nopember, Surabaya, Indonesia. E-mail: itsdesigncenter@yahoo.com. student being normal without past body manipulation. Therefore, data could be considered representative of the size and profile of the Indonesian body. This data was used as a basis to establish formulation and 3D model of the Indonesian body. The ultimate goal was improved function and appearance of patients requiring body contouring where these parameters and 3D model can be used as guidelines for operation, predicting the surgical outcome visually by $3 \mathrm{D}$ modelling.

\section{PURPOSE}

The aim of this study was to build database of clinical anthropometric and photographic parameters of the Indonesian body. This database was applied in making a 3D model of the Indonesian body which may be used as a guideline in improving the function and appearance in patients who require body contouring surgery.

\section{MATERIALS AND METHOD}

\section{A. Study design}

This was a descriptive-analytic-applied study. The of anthropometric and photography database were used to describe morphology of normal and attractive Indonesian bodies. Photographic techniques were also applied in this study in order to get good documentation of the patient, which would be used to describe details of patient's body. This study was also an analytic study comparing shape and measurement of normal and attractive Indonesian female bodies. This was an applied study applying data for developing a 3D model in body contouring surgery.

One hundred questionnaires were filled in by 50 men and 50 women to obtain a criteria of the normal and attractive Indonesian body by Likert scale. The 
respondents then were asked to select deutromelayu women aged 17-25 years and categorize them into 2 groups, normal and attractive. Out of this selection, two hundreds women who never underwent body contouring procedure and consented to participate in this research, had pictures of their bodies taken. Furthermore, out of these 200 women, two juries groups including expert and non expert juries determined 44 bodies considered normal and another 48 assessed as attractive.

These 92 women with normal and attractive had body anthropometric examination and photographic documentation of the body dressed in standardized thin, tight and high elasticity clothes. These were performed by the same examiner and photographer with the same setting and instrument to maintain the consistency of the study.

\section{B. Data analysis}

Data obtained from body anthropometric measurements and photography documentation were used to describe the morphology of normal and attractive Indonesian bodies using tables, graphic and narrative forms. Data of normal and attractive groups were compared and analyzed by t-test and discriminant test. Finally, with adobe photoshop, Poser and 3Dmax software, anthropometric and photographic data were applied for developing 3D woman model of normal and attractive Indonesian bodies for planning and predicting surgical outcome in body contouring surgery.

\section{RESULT}

Criteria of body attractiveness by questionnaire were bright skin color, tallness, slimness, hour glass body shape, muscular arms, medium sized shoulders, hip, waist, breasts and buttocks, wide chest and slender legs.

There were 92 females who undergo the anthropometric measurement and body photography. These 92 pictures then were ranked and classified in 7 Likert scale by 12 non expert juries. There was 1 female in the wonderfully attractive group, 1 female in the very attractive group, 7 females in attractive group, 21 females in rather attractive group, 24 females in normal group, 30 females in unattractive group and 8 in the extremely unattractive group. Figure 3 showed the comparison of subject who represent each Likert scale group.

The picture of subjects were also ranked and classified by 2 expert juries. The maximum value by juries was 69,38 and the minimum value was 56,25 . The average value was 60,70 . The cut off point was 60 . The 48 females who had value more than 60 were classified in attractive group and 44 females who had value less than 60 were classified in normal group. Graphic 1 showed the value of each subject in attractive and normal group.

There were significant differences in body measurement between normal and supernormal groups including chest circumference, chest height, hip width, hip width index, and waist hip ratio (WHR) with $\mathrm{p}<0,05$ by t-test. Table 1 showed the statistical analysis with ttest to all parameters. There were distinguishing parameters between normal and supernormal groups by discriminant test including chest dimension index, waist hip ratio (WHR), triceps skinfold and leg length, showed in table 2.
There were two 3D digital woman models for both normal and supernormal subjects which had measurements approximating the average values of each group. Figure 5 and 6 showed the comparison between 2 models in front and side view. Picture 7 showed the wireframes of 2 models that had been superimposed.

\section{DISCUSSION}

Beauty are different among place and culture9,11. In this study, bright color skin was the most favorite color, similar with research by Smith et al that Asian people like bright skin color more than the dark one22. Tallness was not parameter of attractiveness 4, but from questionnaire, short female was considered to be unattractive, whereas moderate and tall female were have the same value of attractiveness. Female with ideal BMI was considered to be the most attractive, compared to overweight or underweight female, this was similar with research by Tovee,Streeter et al and Singh.11,12,22 There's no research about female arm before, but from questionnaire, muscular arms were considered to be the most attractive arms. Wide chest was more attractive for male respondents, but less attractive for female respondents. This statement was similar with research by Prantl and Barber that male like curvaceous female body more than female for herself.5,10 Curvaceous body was related to breast size. The result from questionnaire was similar with research by Crossley, Harisson, Prantl, that male like big female breast more than female for herself.6,9,10 Waist and hip were related to curvaceous body. Crossley et al, Harisson mentioned that female hip attractiveness was not different for male and female, similar with result from questionnaire in this research.6,9 Male like wide waist more than female, it's different with result from questionnaire.6,9 Swami et al mentioned that in developing country, curvaceous body as "the traditional shape" was more attractive than tubular one, similar with result in this research.4 The slender leg was the most attractive leg reflecting femininity and youthfulness. The leg shape were dichotomies between male and female 7, that's why slender and long leg was always be the most attractive leg for female. Medium sized buttock was the most attractive buttock in this research. The attractive buttock reflected youthfulness and forms smooth natural curve from waist until backside of genu. Male considered wide shoulder as attractive shoulder, it's different with female who like moderate shoulder as the most attractive one.

Since aesthetic surgery is being performed according to surgeons' preferences and ideas of beauty, patients may be dissatisfied with postoperative outcomes. Thus, it should be evaluated, the physical figure that the society prefers and establish standards using more rational approaches.16 In this research, assessment of subject attractiveness had been done by 2 juries groups, expert juries and non expert juries. Expert juries assessed the subject by its body components more than non expert juries who assessed the subject as a totality. Assessment by non expert juries was more subjective whereas expert juries assessment was more objective based on their knowledge about beauty. The most attractive subject based on non expert juries choice had more curvaceous body than expert juries choice, with bigger chest, hip, buttock circumference, bigger BMI, body weight and 
height, and smaller waist and belly circumference. It was similar with Swami's statement 4,that in developing country, the curvaceous body was considered to be more attractive.

There were distinguishing parameters differentiate the normal and attractive group including chest height, inspiration and expiration chest circumference, hip width, hip width index, waist hip ratio (WHR), and arm circumference by t-test. In discriminant test with fisher linear, the distinguishing parameters were chest index, waist hip ratio (WHR), triceps skinfold and leg length.

Chest height was higher in attractive group. There was no research about chest height before, but chest width as horizontal component had been mentioned as determinant factor in body curvature. Chest circumference and chest index as resultant or chest and breast was bigger in attractive group compared to normal group. It was similar to research by Crossley, Harisson, Prant1,6,9,10 that mentioned chest circumference and bigger breast as attractiveness determinant. Hip width as a horizontal component of body curvature was wider in attractive group compared to normal group. It was similar with some previous research mentioned that body curvature is one parameter determining female attractiveness. Hip width was related to waist hip ratio (WHR). WHR was a strong and stable parameter in female attractiveness. WHR reflected reproduction capability so small WHR was considered to be more attractive.10,11 Arm circumference and triceps skinfold were parameters distinguishing normal and attractive group. Arm size was bigger in attractive group compared to normal group, it was similar with questionnaire result. There was no research about arm as attractiveness parameter before. Calf length was the next parameter for female attractiveness. In previous research by Swami, Frederick, was mentioned that leg length was attractiveness parameter of body female.4,7 Different with those previous studies, in this study, only calf length that was considered to be attractiveness parameter, not entire leg length.

\section{CONCLUSION}

There were significant differences in types and measurements between normal and supernormal Indonesian female bodies. Three dimension (3D) digital woman models could serve as tools for distinguishing normal and supernormal bodies visually.

\section{REFERENCES}

[1]. Henss R. Waist-to-hip ratio and attractiveness of the female figure. Evidence from photographic stimuli and methodological considerations. 2000. Pers Individ Dif 28: 501-513 (Cited 20 January 2013).

[2]. Fisher ML, Voracek M. The shape of beauty: determinants of female physical attractiveness. 2006. J Cosmet Dermatol 5: 190194. (Cited 13 January 2013).
[3]. Fan JT, Liu F, Wu J, Dai W. Visual perception of female physical attractiveness. 2004. Proc R Soc Lond B Biol Sci 271: 347-352. (Cited 25 December 2012).

[4]. Swami V, Caprario C, Tovée, M.J, Furnham A. Female physical attractiveness in Britain and Japan: A cross-cultural study. 2006. Eur J Pers 20: 69-81. (Cited 12 January 2013).

[5]. Barber N. Secular Changes in Standards of Bodily Attractiveness in American Women: Different Masculine and Feminine Ideals. 2010. The Journal of Psychology: Interdisciplinary and Applied, 132:1, 87-94. (Cited 12 January 2013).

[6]. Crossley K.L, Cornelissen P.L., Tovée, M.J. What Is an Attractive Body? Using an Interactive 3D Program to Create the Ideal Body for You and Your Partner. 2012. (Cited 20 January 2013).

[7]. Frederick D, Hadji M, Swami V. The influence of leg-to-body ratio (LBR) on judgments of female physical attractiveness: Assessments of computer-generated images varying in LBR. 2010. Body Image. vol 7. pp 51-55. (Cited 20 January 2013).

[8]. Furnham A, Shah K, Body weight, waist-to hip ratio and breast size correlates of ratings of attractiveness and health.Personality and Individual Differences. 2006. Vol 41. pp 443-454. (Cited 5 February 2013).

[9]. Harisson K. Television Viewers' Ideal Body Proportions: The Case of the Curvaceously Thin Woman. 2003. Sex Roles, Vol. 48, Nos. 5/6. (Cited 5 February 2013).

[10]. Prantl L, Grundl M. Males Prefer a Larger Bust Size in Women Than Females Themselves: An Experimental Study on Female Bodily Attractiveness with Varying Weight, Bust Size, Waist Width, Hip Width, and Leg Length Independently. 2011. Aesth Plast Surg. vol. 35: pp 693-702. (Cited 5 February 2013).

[11]. Singh C. Universal Allure of the Hourglass Figure: An Evolutionary Theory of Female Physical Attractiveness. 2006. Clin Plastic Surg.vol 33, 359-370. (Cited 15 December 2012).

[12]. Aston S.J., Steinbreich D.S., Walden J.F., .2009. Aesthetic Plastic Surgery. Elsevier.

[13]. Melvin A, Shiffman A. Body Contouring, Art, Science, and Clinical Practice. 2010. Springer-Verlag Berlin Heidelberg

[14]. Nahai F. The Art of Aesthetic Surgery, Principles and Techniques. Quality Medical Publishing, Inc.`2005.

[15]. Stephen J.M. Plastic Surgery : Trunk And Lower Extremety. Vol 6. Elsevier. 2006.

[16]. Hong Y.J, Park H.S, Lee E.S. Anthropometric Analysis of Waist-to-Hip Ratio in Asian Women. 2009. Aesth Plast Surg (2009) 33:185-190. (Cited 15 December 2012).

[17]. Jonathan CK Wells. Ecogeographical associations between climate and human body composition: Analyses based on anthropometry and skinfolds. 2012. American Journal of Physical Anthropology 147:2, 169-186. (Cited 17 January 2013).

[18]. Lin Y, Wang MJ, Wang EM. The comparisons of anthropometric characteristics among four peoples in East Asia. 2004. Applied Ergonomics. Vol 35(2):173-178. (Cited 17 January 2013)

[19]. Nakanishi Y, Nethery V. Anthropometric comparison between Japanese and Caucasian American male University students. 1999. Appl Human Sci ;18:9-11. (Cited 17 January 2013).

[20]. Esme D.L, Bucksch A., Beekman W.H. Three-Dimensional Laser Imaging as a Valuable Tool for Specifying Changes in Breast Shape After Augmentation Mammaplasty. 2009. Aesthetic Plastic Surgery.pp 191-195. (Cited 25 January 2013).

[21]. Gallo G.,Guarnera G.C., Milanese, F., Modica, D., Catanuto, G., Pane, F. Parametric representation of human breast shapes. 2009. Med. Meas.and App. pp. 26-30. (Cited 20 January 2013).

[22]. Smith KL, Cornelissen PL, Tovée, M.J Color 3D bodies and judgments of human female attractiveness. 2007. Evol Hum Behav 28: 48-54. (Cited 20 January 2013).

[23]. Stephen M.B. The Art of Poser® and Photoshop®:The Official Guide. Course Technology Press Boston, MA, United States. 2009. (Cited 18 February 2013). 


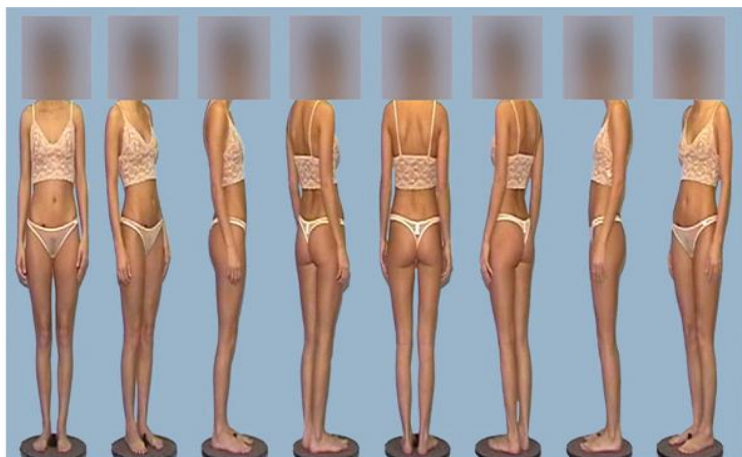

Figure 1. Laser 3D scan for body modeling. Adapted from Smith KL, Cornelissen PL, Tovée, M.J Color 3D bodies and judgments of female attractiveness. 2007. Evol Hum Behav 28: 48-54
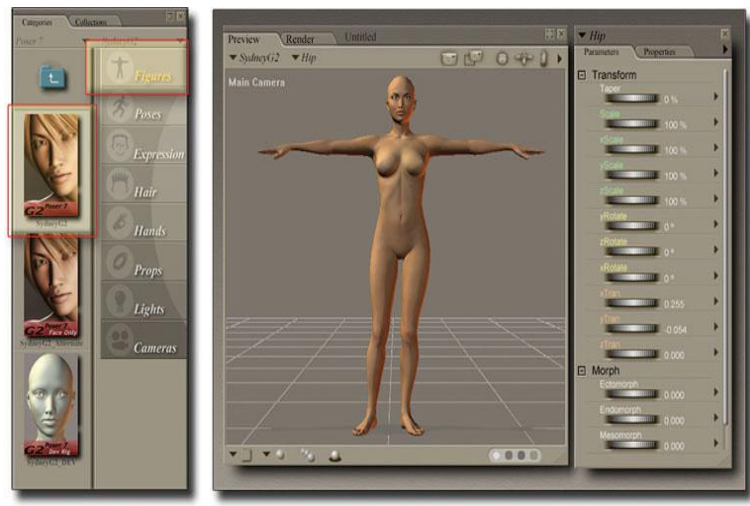

Figure 2. Software Poser, digital body animation. Adapted from Stephen M.B. The Art of Poser® and Photoshop®:The Official Guide Course Technology Press Boston, MA, United States. 2009
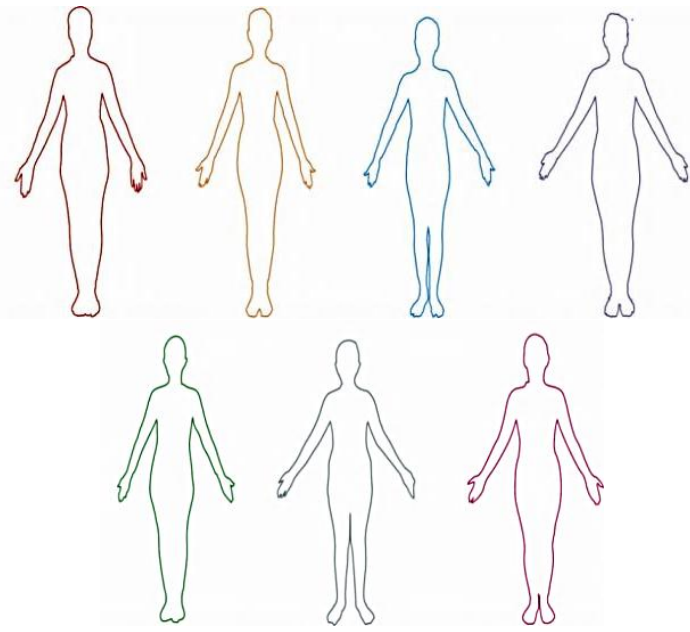

Figure 3. Comparison of subject in each Likert scale Group, Front view
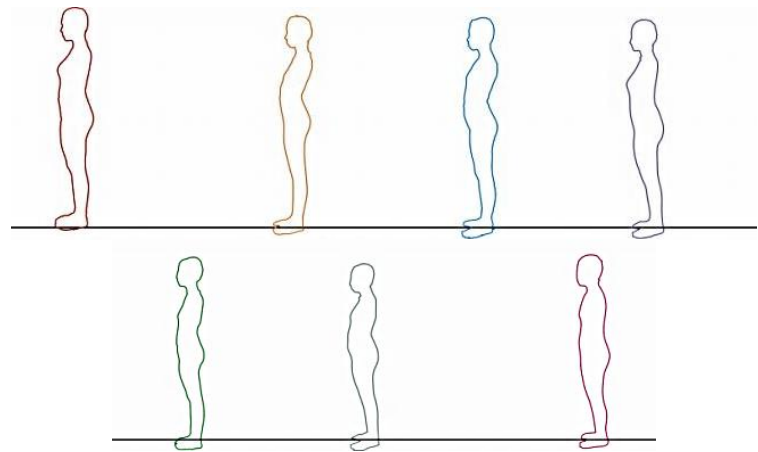

Figure 4. Comparison of subject in each Likert scale Group, Side view

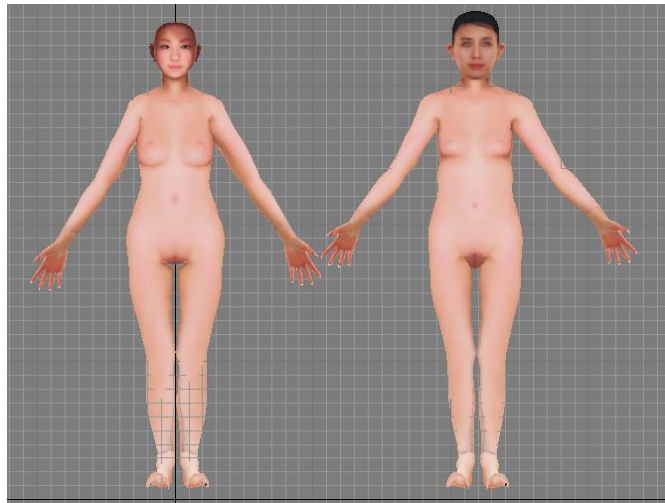

Figure 5. 3D model, front view

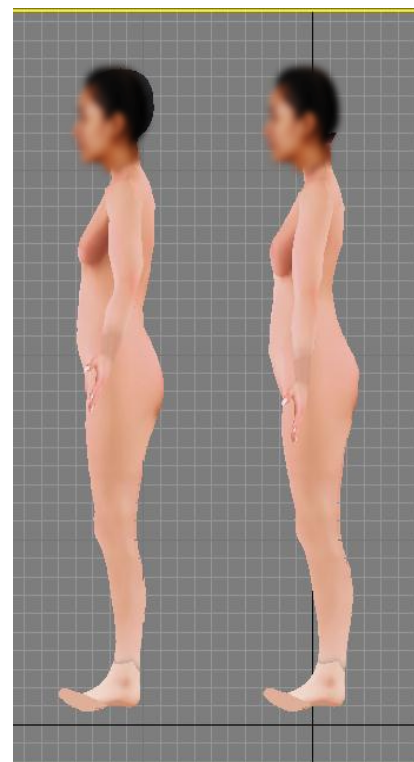

Figure 6. 3D model, side view

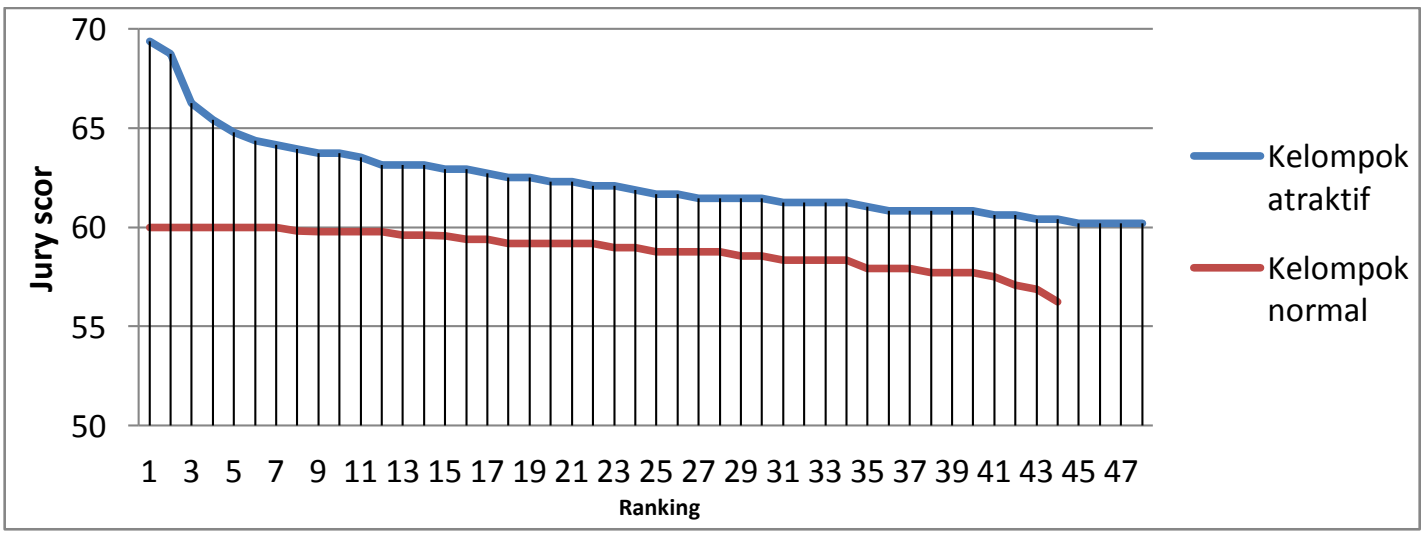

Graphic 1. Expert juries scor, attractive and normal group 
TABLE 1.

STATISTICAL ANALYSIS, T-TEST

\begin{tabular}{|c|c|c|c|}
\hline & $\begin{array}{c}\text { Normal } \\
n=44\end{array}$ & $\begin{array}{c}\text { Attractive } \\
\mathrm{n}=48\end{array}$ & $\begin{array}{c}\text { Statistical analysis } \\
\text { t-test }\end{array}$ \\
\hline Chest height & $18.0909 \pm 1.11163(16.00-20.00)$ & $18.8438 \pm 1.81939(15.00-22.50)$ & $\mathbf{P}<0,05$ \\
\hline $\begin{array}{l}\text { Inspiration chest } \\
\text { circumference }\end{array}$ & $80.8295 \pm 3.88938(74.00-91.00)$ & $83.1354 \pm 5.58754(70.50-95.00)$ & $\mathbf{P}<\mathbf{0 , 0 5}$ \\
\hline $\begin{array}{l}\text { Expiration chest } \\
\text { circumference }\end{array}$ & $78.4886 \pm 4.04263(72.00-89.00)$ & $80.7708 \pm 5.56008(68.50-93.00)$ & $\mathrm{P}<\mathbf{0 , 0 5}$ \\
\hline Hip width & $27.2159 \pm 3.47147(21.00-39.00)$ & $30.3229 \pm 4.21054(24.00-45.00)$ & $\mathbf{P}<\mathbf{0 , 0 5}$ \\
\hline Hip width Index & $17.1227 \pm 2.39213(10.00-24.07)$ & $19.0921 \pm 2.55518(15.15-27.50)$ & $\mathbf{P}<\mathbf{0 , 0 5}$ \\
\hline Waist Hip Ratio & $0.8673 \pm 0.07099(0.71-1.00)$ & $0.7688 \pm 0.05708(0.60-0.84)$ & $\mathbf{P}<\mathbf{0 , 0 5}$ \\
\hline Arm circumference & $24,8068 \pm 2,12191(20,00-29,50)$ & $25,7917 \pm 2,35614(21,50-33,00)$ & $\mathbf{P}<\mathbf{0 , 0 5}$ \\
\hline
\end{tabular}

TABLE 2.

STATISTICAL ANALYSIS, DISCRIMINANT TEST

\begin{tabular}{|c|c|c|}
\hline & Attractive & Normal \\
\hline Chest index & 6,394 & 5,914 \\
\hline Waist hip ratio & 110,822 & 144,324 \\
\hline Right triceps skinfold & 3,078 & 2,544 \\
\hline Left triceps skinfold & 4,697 & 3,924 \\
\hline Calf length & 9,583 & 9,298 \\
\hline
\end{tabular}

